\title{
ASPECTOS FÍSICO-QUÍMICOS E BIOLÓGICOS RELACIONADOS À OCORRÊNCIA DE Biomphalaria glabrata EM FOCOS LITORÂNEOS DA ESQUISTOSSOMOSE EM PERNAMBUCO
}

Petronildo Bezerra da Silva* e Constança Simões Barbosa

Departamento de Parasitologia, Centro de Pesquisas Aggeu Magalhães, FIOCRUZ-Recife, Campus da UFPE,

Av. Prof. Moraes Rego, s/n, 50670-420 Recife - PE, Brasil

Otávio Pieri

Departamento de Biologia Animal, Instituto Oswaldo Cruz, FIOCRUZ-RJ, Av. Brasil, 4365 21045-900 Rio de Janeiro - RJ, Brasil Antônio Travassos

Departamento de Botânica, Universidade Federal Rural de Pernambuco, Rua Dom Manoel de Medeiros, s/n, 52171-030 Recife - PE, Brasil

\section{Lourdinha Florencio}

Departamento de Engenharia Civil, Universidade Federal de Pernambuco, Av. Acadêmico Hélio Ramos, s/n, 50670-530 Recife - PE, Brasil

Recebido em 9/3/05; aceito em 5/1/06; publicado na web em 5/5/06

\begin{abstract}
PHYSICO-CHEMICAL AND BIOLOGICAL ASPECTS RELATED TO THE OCCURRENCE OF Biomphalaria glabrata IN FOCI OF SCHISTOSOMIASIS IN COASTAL AREAS OF THE STATE OF PERNAMBUCO, BRAZIL. This study analyzes the physicochemical and biological parameters of freshwater aquatic environments in coastal areas of the State of Pernambuco, Brazil, where snail vector foci and cases of schistosomiasis have been recorded. The tests were carried out using standard methods and sediments were analyzed using the X-ray fluorescence technique. The micro-algae were analyzed using conventional microscopy. The most abundant chemical elements in the sediments were $\mathrm{Fe}, \mathrm{Ca}, \mathrm{Si}$ and $\mathrm{Al}$ and there were high concentrations of electrolytes in comparison with data published in the literature. The mean values for salinity $(7.7 \mathrm{~g} / \mathrm{L})$ and sulfate $(489 \mathrm{mg} / \mathrm{L})$ were much higher than normal for freshwater environments. The micro-algae identified are those that inhabit environments with higher levels of salinity. The snail Biomphalaria glabrata seems, therefore, to be more tolerant to salty environments and this constitutes a risk of spread of schistosomiasis.
\end{abstract}

Keywords: Biomphalaria glabrata; salinity; aquatic environments.

\section{INTRODUÇÃO}

A esquistossomose mansônica é uma infecção parasitária endêmica de veiculação hídrica, pois parte do ciclo de transmissão da enfermidade ocorre em águas doces infestadas por larvas (cercárias), que são liberadas por caramujos do gênero Biomphalaria. Tem como agente etiológico o helminto Schistosoma mansoni que infecta o ser humano e, eventualmente, outros animais vertebrados ${ }^{1,2}$. Os ovos de $S$. mansoni são eliminados pelas fezes do hospedeiro infectado (homem). Na água, estes eclodem, liberando uma larva ciliada denominada de miracídio, a qual penetra no caramujo. Após quatro a seis semanas o caramujo desenvolve a forma infectante - a cercária - que é liberada nas águas naturais e está pronta para penetrar na pele humana intacta. $\mathrm{O}$ contato humano com as águas contaminadas pelas cercárias é a maneira pela qual o indivíduo adquire a esquistossomose. A doença é considerada endêmica em zonas rurais de países da América Latina, África e Oriente Médio. No entanto, a partir da década de 1980, tem-se constatado o aparecimento de casos da doença em zonas urbanas de grandes cidades. No Brasil, o fenômeno da expansão urbana da esquistossomose é verificado em muitas regiões ${ }^{3-8}$.

Em Pernambuco, casos humanos de infecção aguda têm sido detectados em áreas litorâneas onde a doença foi introduzida'. Essa situação foi desencadeada a partir do êxodo de trabalhadores rurais, muitas vezes infectados pelo $S$. mansoni, em busca de melhores condições de emprego. Esses trabalhadores são inseridos no mercado produtivo

*e-mail: petros@cpqam.fiocruz.br como auxiliares na construção civil ou como prestadores de serviço em hotéis e residências de veranistas, em praias do litoral do Estado. Passam a residir em favelas na periferia dessas praias, em condições insalubres, acabando por contaminar as coleções hídricas disponíveis, muitas delas habitadas por moluscos vetores. Como resultado desse tipo de ocupação, novos sítios de transmissão ativa da doença têm sido detectados em localidades próximas (cerca de $500 \mathrm{~m}$ ) das praias de Itamaracá, Piedade (Jaboatão dos Guararapes) e Porto de Galinhas (município de Ipojuca-PE), todas na região metropolitana do Recife ${ }^{10}$, o que vem causando impacto na população dos municípios afetados e sendo bastante divulgado no meio social ${ }^{11,12}$. No ano de 2000 , na praia de Porto de Galinhas, foram registrados 662 casos de esquistossomose, a maioria em pessoas de classe média e média alta ${ }^{13}$.

A partir da constatação de surtos epidêmicos ocorridos no litoral de Pernambuco e considerando a possibilidade de adaptação/ seleção natural de espécies de caramujos antes restritos ao ambiente de água doce e agora presentes em zonas costeiras, procurouse investigar os parâmetros físico-químicos (salinidade, amônia, sulfatos, dentre outros) e biológicos (microalgas) relacionados à sobrevivência do vetor Biomphalaria glabrata. As modificações induzidas pelo homem e as características próprias de ambientes litorâneos com teores salinos elevados podem levar à apresentação de poluentes acima dos níveis até então conhecidos como toleráveis por tal espécie de vetor, podendo conduzir à seleção de populações de caramujos resistentes.

De acordo com vários autores ${ }^{14-16}$, a qualidade da água é muito importante na distribuição dos caramujos vetores da esquistossomose. Muitos fatores e parâmetros envolvem a qualidade das 
águas, os quais devem ser considerados e relacionados à sobrevivência do vetor para assim se poder compreender sua presença em criadouros litorâneos.

Os estudos mais recentes sobre as condições ambientais de sobrevivência do vetor Biomphalaria glabrata no litoral de Pernambuco foram realizados há cerca de 20 anos, por Pieri ${ }^{17}$. Durante este período, é razoável considerar que os ambientes aquáticos urbanoslitorâneos tenham sofrido variação na sua composição físico-química, devido a agentes poluidores disseminados pela ação antrópica.

O presente estudo foi realizado para avaliar a atual composição química e biológica de alguns ambientes aquáticos litorâneos do Estado de Pernambuco, no qual predomina a espécie Biomphalaria glabrata, com vistas à possibilidade da elaboração de estratégias específicas para controle desse molusco, vetor de S. mansoni.

\section{PARTE EXPERIMENTAL}

\section{Características sócio-ambientais das áreas de estudo}

As áreas de estudo foram definidas tendo como base os registros de focos ativos de transmissão da esquistossomose através de inquéritos epidemiológicos realizados por Gonçalves ${ }^{18}$, Barbosa et al. ${ }^{9,13,19}$ e Barbosa e Pieri ${ }^{6}$ em localidades de municípios litorâneos na Região Metropolitana do Recife, tais como Itamaracá, Porto de Galinhas (Ipojuca) e na Lagoa Olho D'água em Jaboatão dos Guararapes. Nesses trabalhos, todos os condicionantes ambientais que interferem na expansão de uma endemia de veiculação hídrica, como a esquistossomose, foram caracterizados, tais como migração interna, recursos naturais, ocupação e uso do solo e condições sanitárias do meio. Esses estudos foram nossas fontes de referência para resgatar informações sobre as áreas de estudo consideradas neste trabalho.

A Ilha de Itamaracá situa-se no litoral norte de Pernambuco a 42 $\mathrm{km}$ do Recife. Na ilha foram escolhidas as localidades de Enseada dos Golfinhos e Praia do Forte, possuidoras de grande variedade de fontes hídricas, perenes e temporárias, como valas, charcos localizados em terrenos baldios, poças d’água e lagoas.

Localizada no lado leste da Ilha de Itamaracá, a Praia do Forte possui cerca de $2 \mathrm{~km}$ de orla marítima e é uma das localidades preferidas por turistas e veranistas. Estes são em sua maioria de classe média/alta.

Segundo o último inquérito malacológico realizado na área, a transmissão da esquistossomose ocorre em maior intensidade na época de pós-chuvas (setembro a dezembro), que reúne condições sócioambientais favoráveis para a ocorrência de casos novos, em virtude do incremento da densidade populacional de moluscos vetores e da presença de visitantes ${ }^{19}$.

No município de Jaboatão dos Guararapes, a $15 \mathrm{~km}$ do Recife, encontra-se a Lagoa Olho D'água, distante cerca de $500 \mathrm{~m}$ da Praia de Piedade. É uma lagoa extremamente rasa e com dois canais principais de alimentação: o canal Setúbal ao norte e o canal Olho D’água. A alimentação da lagoa está condicionada às precipitações pluviométricas, aos afloramentos do lençol freático e às águas oceânicas que são distribuídas pela lagoa de modo cíclico por meio do canal Olho D'água ${ }^{20}$.

$\mathrm{Na}$ estação das chuvas, devido à baixa capacidade de drenagem da área, ocorre transbordamento das águas da lagoa e inundações nas comunidades vizinhas, facilitando a transmissão de doenças de veiculação hídrica, como leptospirose, esquistossomose e hepatites $^{21,22}$.

De acordo com a Fundação para o Desenvolvimento dos Municípios de Pernambuco-FIDEM, apenas 10,6\% de todo o município são atendidos pela rede de esgoto ${ }^{23}$. A prefeitura desenvolveu um pro- grama de obras de esgotamento sanitário para cerca de 5.000 famílias das 11 áreas de baixa renda do em torno da lagoa. Mas, diante da limitação dos recursos não foi possível a conclusão das obras.

A praia Porto de Galinhas pertence ao município de Ipojuca, localizado na Região Metropolitana do Recife, distante $60 \mathrm{~km}$ da capital.

Nas comunidades de Salinas e Pantanal, foram escolhidos quintais de casas e charcos situados próximos ao mangue, cujas águas contribuem com as enchentes em caso de grandes precipitações pluviométricas. Essas comunidades foram surgindo a partir da ocupação desordenada de famílias provenientes do interior de Pernambuco.

Segundo Barbosa et al. ${ }^{13}$, os caramujos vetores da esquistossomose teriam sido introduzidos em Porto de Galinhas através do transporte de areia dos leitos de rios oriundos de localidades endêmicas. A Figura 1 mostra a localização das áreas estudadas.

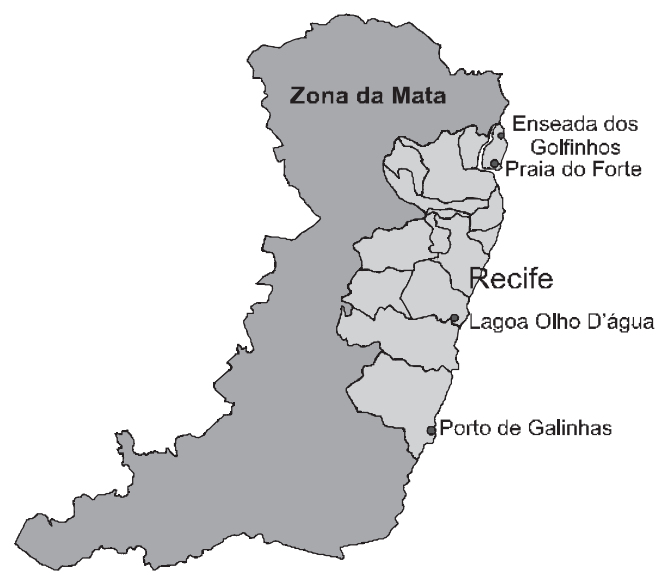

Figura 1. Localização das áreas de estudo

\section{Amostragem}

Para avaliar a concentração dos diversos fatores físico-químicos no ambiente aquático dos moluscos vetores, foram realizadas coletas bimensais de água nas estações seca e chuvosa de setembro de 2002 a dezembro de 2003, em sete pontos demarcados, identificados como sendo de ocorrência do vetor Biomphalaria glabrata e considerados de transmissão recente da esquistossomose.

\section{Locais avaliados}

Na Ilha de Itamaracá, um charco situado na localidade de Forte Orange (Charco Orange) e outro na praia Enseada dos Golfinhos (Lagoa da Constança); em Porto de Galinhas, dois pontos situados nas comunidades de Salinas (Tanque Salinas e Charco Salinas) e em um alagado temporário em Pantanal e em Piedade, um ponto na margem direita da Lagoa Olho D'água - na comunidade de Dom Helder - e outro em um canal de drenagem que recebe os esgotos das residências do em torno da lagoa, chamado de Esgoto Olho D’água.

\section{Medidas e testes}

Os parâmetros físico-químicos foram medidos de acordo com Clesceri et al. ${ }^{24}$. Foram coletados em cada ponto $5 \mathrm{~L}$ de água, em frascos de polietileno, próximos à superfície, com cuidado, para não perturbar muito a região de coleta. Foram analisados in situ temperatura, salinidade, sólidos totais dissolvidos e condutividade elétrica, utilizando-se um multianalisador da marca Schott, modelo Handlab1. As amostras de água foram acondicionadas em cai- 
xas de isopor mantidas sob resfriamento com barras de gelo do tipo gelock e guardadas em refrigeração a $4{ }^{\circ} \mathrm{C}$ até o momento das análises. Todas as análises físico-químicas no laboratório foram realizadas em triplicata.

A análise do sedimento foi importante para enfatizar o papel que este componente tem no processo de fixação do vetor em ambientes costeiros e interioranos, pois sendo seres detritivos, os caramujos utilizam também substâncias do sedimento para auxiliar na sua alimentação ${ }^{17,25}$. Os sedimentos foram coletados em vários pontos das margens dos corpos d'água com ajuda de espátula de aço inoxidável, misturados, homogeneizados e guardados em sacos plásticos. Foram coletadas duas amostras na estação seca e duas na estação chuvosa. As amostras (fração silte-argila) foram secas em estufa a $100{ }^{\circ} \mathrm{C}$ por $24 \mathrm{~h}$, e finamente pulverizadas $(\cong 200$ mesh) com um almofariz e pistilo de ágata. Tomou-se 1,0 g ( \pm $0,0001)$ da amostra para ensaio da perda ao fogo em mufla a 1000 ${ }^{\circ} \mathrm{C}$ por $2 \mathrm{~h}$. As amostras foram analisadas qualitativamente para elementos pesados e alguns leves e semi-quantitativamente para alguns elementos detectados na varredura qualitativa através da técnica de fluorescência de raios $X$, utilizando-se um espectrofotômetro de fluorescência de raios X, Rigaku modelo RIX 3000, equipado com tubo Rh.

Para análise das microalgas, foram coletadas amostras de água em recipientes plásticos com capacidade de $5 \mathrm{~L}$, aos quais foram adicionados $50 \mathrm{~mL}$ de solução de lugol com $20 \%$ de ácido acético glacial para fixação e coloração do material biológico. No laboratório aguardou-se a sedimentação espontânea do material, retirouse cerca de $60 \mu \mathrm{L}$, que foi transferido para uma lâmina e, em seguida, coberto com uma lamínula. Foram preparadas lâminas com o material corado, o qual foi visualizado em microscópio composto da marca Zeiss.

Vale salientar que a durante as campanhas de coleta de água procurou-se fazer um registro da presença ou ausência de caramujos da espécie Biomphalaria glabrata em cada ponto de coleta.

\section{RESULTADOS E DISCUSSÃO}

\section{Análise físico-química das águas}

Os resultados das análises físico-químicas mostraram que a Lagoa Olho D'água exibiu maior variabilidade dos componentes salinos, o que mostra bem a dimensão do grau de salinidade tolerado pele caramujo vetor Biomphalaria glabrata. Esse comportamento pode ser melhor observado na Figura 2. Com relação às outras localidades, observam-se características de água doce (CONAMA 20/86) ${ }^{26}$.

Em virtude desses resultados foi feita uma análise comparativa dos dados da Lagoa com a literatura e os limites ambientais do CONAMA, conforme mostrado na Tabela 1.

Estes resultados foram bem maiores que aqueles apresentados por outros autores ${ }^{14-16,27-35}$ para ambientes naturais de vetores da esquistossomose, que mostraram valores de condutividade e salinidade oscilando entre as faixas doce e salobra da classificação do CONAMA, com intervalos de variação de 117 a $2.000 \mu \mathrm{S} / \mathrm{cm}$. Portanto, os resultados apresentados neste trabalho mostram certa tendência do vetor em estar selecionado em um ambiente com características naturais e poluentes bem diversas daquelas apresentadas em um meio dulcícola.

As águas da Lagoa Olho D'água tiveram seus valores do conteúdo salino (cloretos, condutividade, TDS, dureza e salinidade) mais acentuados, ultrapassando os limites encontrados na literatura e nos padrões ambientais. A média de salinidade está cerca de 15 vezes maior que o máximo aceito para água doce, o que representa uma nova condição físico-química de sobrevivência da espé-

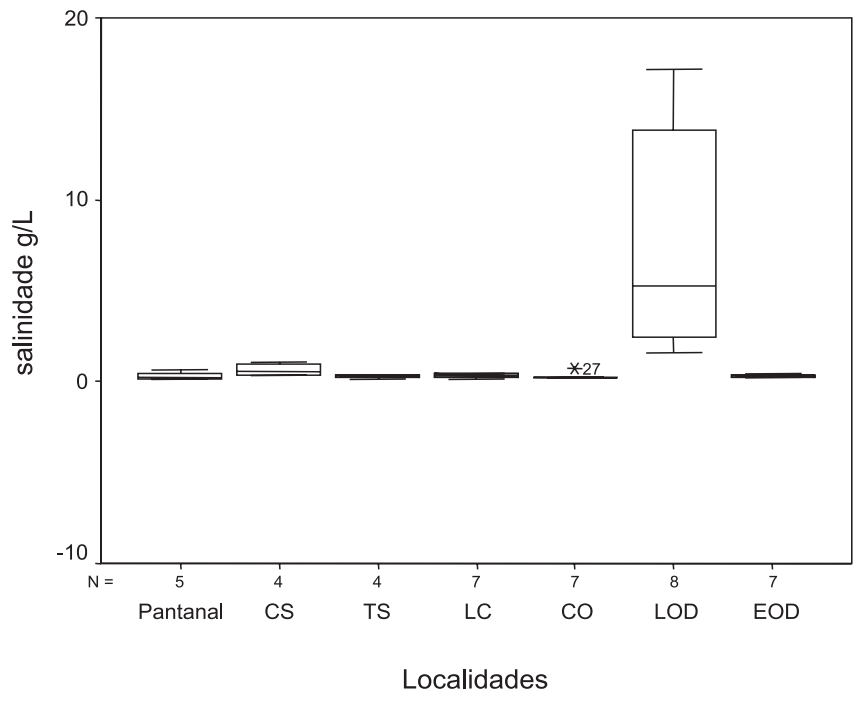

Figura 2. Variação dos valores de salinidade das amostras de água coletadas nas localidades de Pantanal, Salinas (CS) e Tanque Salinas (TS) em Porto de Galinhas; Lagoa da Constança (LC) e Charco Orange (CO) em Itamaracá e Lagoa Olho D'água (LOD) e o Esgoto Olho D'água (EOD) em Jaboatão dos Guararapes

cie vetora, já que os moluscos da espécie Biomphalaria glabrata são considerados típicos de água doce. Os dados elevados de sulfato indicam influência de fluxos de maré na área estudada, o que confirma mais um aspecto salino do meio. Constata-se também a tolerância do vetor a ambientes que reúnem uma grande variabilidade na concentração de sais.

A comparação foi realizada com águas de classe 2, na qual a maioria das águas superficiais de Pernambuco se enquadra, segundo a Agência de Meio Ambiente e Recursos Hídricos de Pernambuco ${ }^{36}$.

Outro dado importante relativo às análises físico-químicas das águas foram os valores de amônia. A amônia, considerada tóxica para muitos organismos aquáticos, foi encontrada em maior quantidade no Esgoto Olho D'água e neste local foram achados caramujos sobrevivendo com teores médios de amônia de 39,2 g/L (Figura 3), sem ter sido constatado, visivelmente, nenhuma alteração na

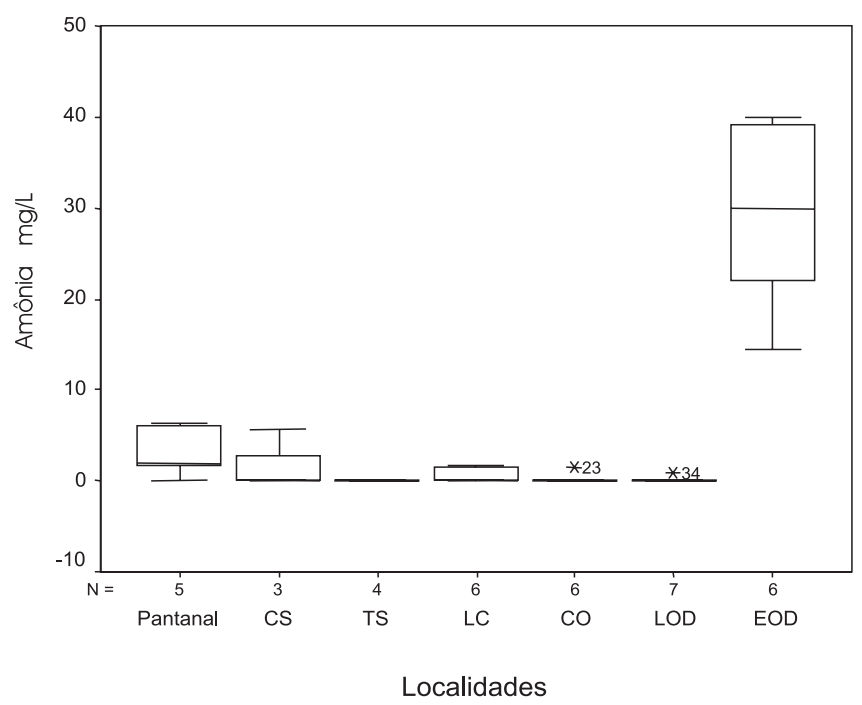

Figura 3. Variação de amônia nas localidades de Pantanal, Salinas (CS) e Tanque Salinas (TS) em Porto de Galinhas; Lagoa da Constança (LC) e Charco Orange (CO) em Itamaracá e Lagoa Olho D'água (LOD) e Esgoto Olho D'água (EOD) em Jaboatão dos Guararapes 
Tabela 1. Comparação entre os dados da Lagoa Olho D’água, da literatura de ambientes aquáticos de Biomphalaria glabrata e do CONAMA

\begin{tabular}{|c|c|c|c|c|c|c|c|c|}
\hline Parâmetros & $\mathrm{N}$ & Média & DP & Mínimo & Máximo & Mediana & Lit. & $\begin{array}{c}\text { CONAMA } \\
\text { 20/86 classe } 2\end{array}$ \\
\hline $\mathrm{T}^{\circ} \mathrm{C}$ & 8 & 31,56 & 2,35 & 29,00 & 36,50 & 31,00 & 41 & - \\
\hline $\mathrm{pH}$ & 8 & 7,88 & 0,45 & 7,30 & 8,50 & 7,80 & 9,1 & $6,0-9,0$ \\
\hline cond. $\mu \mathrm{S} / \mathrm{cm}$ & 8 & 13137,50 & 10142,99 & 2610,00 & 28700,00 & 9515,00 & 2000 & - \\
\hline sal. g/L & 8 & 7,73 & 6,24 & 1,60 & 17,20 & 5,30 & - & 0,5 \\
\hline TDS mg/L & 8 & 7853,38 & 6265,75 & 1356,00 & 17600,00 & 6325,00 & - & 500 \\
\hline OD mg/L & 24 & 8,58 & 4,55 & 1,80 & 17,20 & 8,00 & - & 35 \\
\hline cloretos mg/L & 24 & 14277,00 & 30378,51 & 769,00 & 88978,00 & 2967,00 & 3500 & 250 \\
\hline cor & 24 & 245,00 & 164,06 & 60,00 & 500,00 & 175,00 & - & 75 \\
\hline turb. NTU & 24 & 68,78 & 67,85 & 16,70 & 207,00 & 43,50 & 230 & 100 \\
\hline alcalinidade $\mathrm{mg} / \mathrm{L}$ & 24 & 291,00 & 94,70 & 140,00 & 428,00 & 279,00 & 415 & - \\
\hline dureza $\mathrm{mg} / \mathrm{L}$ & 24 & 1764,83 & 1285,29 & 554,00 & 3700,00 & 1172,00 & 980 & - \\
\hline DQO mg/L & 24 & 1443,63 & 926,89 & 263,00 & 2692,00 & 1298,50 & - & - \\
\hline $\mathrm{NO}_{2} \mathrm{mg} / \mathrm{L}$ & 24 & 0,00 & 0,00 & 0,00 & 0,00 & 0,00 & - & 1 \\
\hline $\mathrm{NO}_{3}^{2} \mathrm{mg} / \mathrm{L}$ & 21 & 0,08 & 0,08 & 0,00 & 0,21 & 0,10 & - & 10 \\
\hline $\mathrm{NH}_{3}^{3} \mathrm{mg} / \mathrm{L}$ & 21 & 0,10 & 0,28 & 0,00 & 0,80 & 0,00 & 0,5 & 0,02 \\
\hline $\mathrm{Fe} \mathrm{mg} / \mathrm{L}$ & 21 & 0,33 & 0,19 & 0,10 & 0,63 & 0,32 & 5,4 & 0,3 \\
\hline $\mathrm{Na}^{+} \mathrm{mg} / \mathrm{L}$ & 21 & 2015,13 & 1993,46 & 365,60 & 5800,00 & 1275,00 & 750 & - \\
\hline $\mathrm{K}^{+} \mathrm{mg} / \mathrm{L}$ & 21 & 94,33 & 82,69 & 30,00 & 250,00 & 65,00 & 54,5 & - \\
\hline $\mathrm{Ca}^{2+} \mathrm{mg} / \mathrm{L}$ & 21 & 352,84 & 358,82 & 89,00 & 1120,00 & 285,00 & 129 & - \\
\hline $\mathrm{SO}_{4}^{2-} \mathrm{mg} / \mathrm{L}$ & 21 & 488,90 & 429,52 & 65,00 & 1296,00 & 437,00 & 255 & 250 \\
\hline DBO mg/L & 18 & 98,33 & 58,11 & 40,00 & 200,00 & 90,00 & - & 5 \\
\hline ST mg/L & 18 & 8915,33 & 8557,71 & 2012,00 & 22636,00 & 4831,50 & - & - \\
\hline STF mg/L & 18 & 6971,00 & 6945,94 & 1544,00 & 17934,00 & 3343,00 & - & - \\
\hline STV mg/L & 18 & 1945,17 & 1700,81 & 468,00 & 4705,00 & 1502,00 & - & - \\
\hline $\mathrm{PO}_{4}^{3-} \mathrm{mg} / \mathrm{L}$ & 9 & 0,44 & 0,30 & 0,10 & 0,67 & 0,54 & - & 0,025 \\
\hline
\end{tabular}

morfologia dos caramujos. O limite máximo que já pode inibir o crescimento da espécie é de $25 \mathrm{mg} / \mathrm{L}^{37}$.

Registrou-se a presença de exemplares Biomphalaria glabrata durante todos os períodos de coleta, especialmente no período logo após as chuvas, o que representa um bom aporte de água e calor nos criadouros dos moluscos vetores ${ }^{19}$.

\section{Análise dos sedimentos}

Os resultados da análise dos sedimentos estão apresentados na Tabela 2.

De acordo com o resultado das análises dos sedimentos, os elementos químicos mais abundantes nesses ambientes foram $\mathrm{Si}, \mathrm{Al}, \mathrm{Fe}$ e Ca.

O ferro e o cálcio relacionam-se diretamente com a sobrevivência do caramujo vetor. O cálcio é necessário ao processo de biomineralização da concha ${ }^{38}$ e o ferro é parte da hemoglobina e da ferritina $^{39}$. Através de mecanismos de troca de metais presentes no sedimento e o meio aquoso, esses metais são disponibilizados para o caramujo que, por meio da ingestão de água, os sintetiza formando as metaloproteínas, fundamentais ao seu desenvolvimento. Esse processo de troca de metais é representado de certa forma por um equilíbrio químico dinâmico do meio, pois ao mesmo tempo em que se tem a fixação dos metais no sedimento da lagoa, tem-se também a solubilização dos complexos metálicos pelas condições ambientais, tais como salinidade, $\mathrm{pH}$, temperatura e hidrodinâmica ${ }^{40}$.

$\mathrm{O} \mathrm{Cr}$, metal pesado de elevado potencial tóxico aos ecossistemas aquáticos, apresentou-se em maior quantidade na Lagoa Olho D'água.

O Sr teve uma concentração de $0,58 \%$ na Lagoa da Constança. Pertencente à família dos metais alcalinos terrosos, é de grande importância para espécies de caramujos pois, na falta momentânea de cálcio, os caramujos vetores conseguem substituir este elemento pelo estrôncio ${ }^{41}$.
O charco Salinas apresentou a maior concentração de matéria orgânica nos sedimentos. Durante as coletas, foram encontrados vários resquícios de conchas de caramujos, o que pode ter contribuído para os altos valores deste parâmetro neste microambiente.

\section{Análise das microalgas}

Nos ecossistemas de água doce, a biomassa fitoplanctônica é constituída em parte por microalgas que são as principais responsáveis pelo suprimento alimentar da cadeia trófica, contribuindo para a sobrevivência da espécie Biomphalaria glabrata e conseqüente manutenção dos focos litorâneos da esquistossomose. Observações anteriores sobre a associação de microalgas e a abundância de Biomphalaria glabrata em charcos interioranos mostraram que o fitoplâncton nesses ambientes apresentava-se com uma grande diversidade de espécies, facilitando a proliferação de caramujos vetores ${ }^{42,43}$. Resultados semelhantes foram obtidos nas áreas litorâneas de Pernambuco. Estavam presentes nas amostras várias espécies de Cyanobacteria, Chlorophyta, Bacillariophyta, Euglenophyta e, em menor freqüência, espécies de Xanthophyta e Pgrophyta. Todas as espécies encontradas são representantes do plâncton de água doce. O Filo Chlorophyta apresentou-se mais distribuídos em razão de apresentar, de acordo com a literatura, a maior diversidade de espécies nos ambientes aquáticos ${ }^{44}$.

Na Lagoa Olho D'água destaca-se a espécie Chaetocerus diversus que pode viver tanto em meios dulcícolas como em ambiente marinho, o que constitui um indicador biológico valioso para a caracterização das águas da lagoa como bem salinizadas.

Entre os ambientes analisados, as Lagoas da Constança com características dulcícolas e a Olho D’água com características físico-químicas salobras apresentaram-se com maior quantidade e diversidade de espécies fitoplanctônicas, algumas até em floração. 
Tabela 2. Resultados das análises dos sedimentos

\begin{tabular}{|c|c|c|c|c|c|c|}
\hline$\%$ & $\begin{array}{l}\text { Charco Orange } \\
\text { Itamaracá-PE }\end{array}$ & $\begin{array}{l}\text { Lagoa Olho D'água } \\
\text { Jaboatão-PE }\end{array}$ & $\begin{array}{l}\text { Lagoa da Constança } \\
\text { Itamaracá-PE }\end{array}$ & $\begin{array}{l}\text { Esgoto Olho D’água } \\
\text { Jaboatão-PE }\end{array}$ & $\begin{array}{l}\text { Pantanal-P.de } \\
\text { Galinhas-PE }\end{array}$ & $\begin{array}{l}\text { Charco Salinas } \\
\text { P. de Galinhas-PE }\end{array}$ \\
\hline $\mathrm{SiO}_{2}$ & 52,63 & 57,15 & 37,99 & 65,27 & 65,29 & 16,62 \\
\hline $\mathrm{Al}_{2} \mathrm{O}_{3}$ & 20,47 & 3,16 & 1,2 & 18,72 & 9,7 & 4,18 \\
\hline $\mathrm{CaO}$ & 1,06 & 14,24 & 42,75 & 1,76 & 4,12 & 4,2 \\
\hline $\mathrm{Fe}_{2} \mathrm{O}_{3}$ & 10,78 & 5,35 & 1,22 & 5,37 & 3,72 & 10,18 \\
\hline $\mathrm{TiO}_{2}$ & 2,91 & 0,62 & 0,3 & 1,6 & 1,49 & 0,78 \\
\hline $\mathrm{P}_{2} \mathrm{O}_{5}$ & 1,02 & 1,28 & 0,85 & 1,36 & 2,55 & 1,35 \\
\hline $\mathrm{SO}_{3}$ & 0,7 & 6,28 & 1 & 0,83 & 1,7 & 12,34 \\
\hline $\mathrm{K}_{2} \mathrm{O}$ & 0,41 & 1,95 & 0,55 & 0,76 & 3,33 & 2,17 \\
\hline $\mathrm{Cr}_{2} \mathrm{O}_{3}$ & 0,05 & 0,1 & 0,06 & 0,05 & 0,06 & 0,02 \\
\hline $\mathrm{MnO}$ & 0,04 & 0,03 & - & 0,01 & 0,03 & 0,05 \\
\hline $\mathrm{ZrO}_{2}$ & 0,4 & 0,12 & - & 0,09 & 0,15 & 0,13 \\
\hline $\mathrm{CuO}$ & & 0,01 & & 0,01 & 0,08 & 0,01 \\
\hline $\mathrm{ZnO}$ & 0,01 & 0,01 & & 0,02 & 0,03 & 0,08 \\
\hline $\mathrm{SrO}$ & 0,01 & 0,07 & 0,58 & 0,01 & 0,03 & 0,08 \\
\hline $\mathrm{NiO}$ & 0,02 & 0,02 & 0,02 & 0,01 & 0,02 & 0,01 \\
\hline $\mathrm{Na}_{2} \mathrm{O}$ & & 0,41 & & & & 0,12 \\
\hline $\mathrm{MgO}$ & & 0,45 & & 0,08 & & 0,27 \\
\hline $\mathrm{Ga}_{2} \mathrm{O}_{3}$ & 0,01 & & & & & \\
\hline $\mathrm{Br}$ & & 0,03 & 0,01 & & & 0,03 \\
\hline $\mathrm{Rb}_{2} \mathrm{O}$ & & 0,01 & & & 0,01 & 0,02 \\
\hline $\mathrm{Nb}_{2} \mathrm{O}_{5}$ & 0,01 & & & & & \\
\hline $\mathrm{BaO}$ & & & & & & 0,06 \\
\hline $\mathrm{PbO}$ & 0,01 & & & & 0,01 & 0,01 \\
\hline PF & 9,41 & 8,71 & 13,47 & 4,02 & 7,65 & 47,25 \\
\hline Total & 99,95 & 100 & 100 & 99,97 & 99,97 & 99,96 \\
\hline
\end{tabular}

$\mathrm{PF}=$ Perda ao fogo

Na Lagoa da Constança observou-se Euglena sp e na Lagoa Olho D'água a espécie em floração foi a Microcystis aeruginosa, que se constituem em bons indicadores biológicos de saprobidade e poluição das águas. As espécies de gênero Scenedesmus foram registradas com maior frequiência na Lagoa da Constança, o que ressalta mais um aspecto das águas doces desse ambiente.

Dentre as Cyanobactérias, as espécies do gênero Oscilatoria foram freqüentes e com relação às Chlorophytas constantou-se espécies de Oocytis no Charco de Orange, no Tanque Salinas e na Lagoa da Constança. Sendo assim, vale considerar que a diversidade das espécies encontradas nos criadouros litorâneos de Pernambuco reflete a importância desses focos na manutenção e sobrevivência do caramujo Biomphalaria glabrata

\section{CONCLUSÕES}

As populações de Biomphalaria glabrata resistem a valores ambientais físico-químicos bem acima dos referenciados na literatura. Neste aspecto, as águas coletadas na Lagoa Olho D’água são salobras, em grau acentuado, com média geral de salinidade cerca de 15 vezes maior que o padrão máximo aceito para as águas doces, que é de $0,5 \mathrm{~g} / \mathrm{L}$. As análises de fitoplâncton sugerem que a diversidade de espécies de microalgas encontradas contribui para a proliferação de Biomphalaria glabrata, fornecendo alimento à cadeia trófica. As altas concentrações de ferro, cálcio e matéria orgânica no sedimento podem ajudar no desenvolvimento do caramujo vetor. Sendo assim, a diversidade de fatores ecológicos analisados neste trabalho contribui para a que o molusco Biomphalaria glabrata possa colonizar criadouros também diversos, aumentando as possibilidades de expansão da esquistossomose.
Os resultados das análises realizadas nas áreas litorâneas do Estado de Pernambuco mostram que o referido animal constitui-se em uma espécie vetora extremamente tolerante à variabilidade de concentrações salinas nas águas e nos sedimentos, o que torna difícil qualquer medida de controle ambiental do molusco baseada exclusivamente na manipulação de dados ecológicos. Por outro lado, é possível recomendar aos órgãos de vigilância em saúde ambiental maior atenção em áreas estuarinas salobras, bem como o monitoramento da tendência de salinização das águas em regiões endêmicas para a esquistossomose.

\section{AGRADECIMENTOS}

Aos técnicos de campo do Serviço de Referência Regional de Esquistossomose do Centro de Pesquisas Aggeu Magalhães-CPqAM/ FIOCRUZ/Recife. À Profa. Dra. V. P. Ferreira do Departamento de Geologia da UFPE pela ajuda nas análises dos sedimentos.

\section{REFERÊNCIAS}

1. Rey, L.; Parasitologia Médica, $2^{\mathrm{a}}$ ed., Guanabara Koogan: Rio de Janeiro, 1992, cap. 33.

2. Melo, A. L.; Zech e Coelho, P. M. Em Parasitologia Humana; Neves, D. P., ed.; $2^{\mathrm{a}}$ ed., Atheneu: São Paulo, 2003, cap. 31.

3. Silva, L. J. da; Revista de Saúde Pública 1985, 19, 1.

4. Almeida, Y. M.; Souza-Filho, J. V.; Bringel, M. J. A.; Barros Jr., E. A.; Dias Jr., E. A.; Revista do Instituto de Medicina Tropical de São Paulo 1991, 33, supl. 1, 48 .

5. Lima, V. L. C.; Cadernos de Saúde Pública 1995, 11, 45.

6. Barbosa, C. S.; Gonçalves, J. F.; Albuquerque, Y.; Barbosa, F. S.; Memórias do Instituto Oswaldo Cruz 1998, 93, 265. 
7. Barata, C. H.; Neto, H. V. S.; Cunha, I. C. L.; Rodrigues Jr., V.; Prata, A.; Revista da Sociedade Brasileira de Medicina Tropical 2000, 33, 379.

8. Silva, A.; Santana, L. B.; Jesus, A. R.; Burattini, M. N.; Carvalho, E.; Revista da Sociedade Brasileira de Medicina Tropical 2000, 33, 376.

9. Barbosa, C. S.; Silva, C. B.; Barbosa, F. S.; Revista de Saúde Púbica 1996, 30, 609 .

10. Favre, T. C.; Pieri, O. S.; Barbosa, C. S.; Beck, L.; Revista da Sociedade Brasileira de Medicina Tropical 2001, 34, 569.

11. Jornal do Commercio, Caderno Cidades: Recife, edição de 17/09/02.

12. Folha de Pernambuco, Caderno Grande Recife: Recife, edição de 22/03/ 03.

13. Barbosa, C. S.; Domingues, A. L. C.; Abath, F.; Montenegro, S. M. L.; Guida, U.; Carneiro, J.; Tabosa, B.; Morais, C. N. L.; Spinelli, V.; Cadernos de Saúde Pública 2001, 17, 725.

14. Harry, H. W.; Cumbie, B. G.; Jesus, J. M. de; The Am. J. Tropical Medicine and Hygiene 1957, 6, 313.

15. Pimentel, D.; White Jr., P. C.; Ecology 1959, 40, 533.

16. Harrison, A. D.; Mckillop,W. B.; Arch. Hydrobiological 1980, 57, 251.

17. Pieri, O. S.; Tese de Doutorado, University of Sussex, U.K., 1985.

18. Gonçalves, J. F.; Coutinho, A.; Santana, W.; Barbosa, C. C. G. S.; Cadernos de Saúde Pública 1992, 7, 424.

19. Barbosa, C. S.; Pieri, O. S.; Silva, C. B.; Barbosa, F. S.; Revista de Saúde Pública 2000, 34, 337.

20. Companhia de Pesquisa em Recursos Minerais; Diagnóstico do Meio Físico da Bacia da Lagoa Olho D'água, Recife, 1997.

21. Florencio, L.; Kato, M. T.; Lima, E. S. de; Environ. Int. 2001, 26, 551.

22. Honorato, E. V.; Tese de Doutorado, Universidade Federal de Pernambuco, Brasil, 2002.

23. Fundação para o Desenvolvimento dos Municípios de Pernambuco, Recife; Perfil Municipal - Base de Dados, 1999.

24. Clesceri, L. S.; Greenberg, A. F.; Eaton, A. D.; Frason, M. A., eds.; Standard Methods for the Examination of Water and Wastewater, $19^{\text {th }} \mathrm{ed}$.; United Book Press, Inc.: Washington, D.C., 1995.

25. Barbosa, F. S.; Barbosa, C. S.; Cadernos de Saúde Pública 1994, 10, 200.
26. Resolução $\mathrm{N}^{\circ} 20$ do Conselho Nacional do Meio-Ambiente (CONAMA), de 18 de junho de 1986, Diário Oficial da União, 30/07/1986.

27. Luttermoser, G. W.; Castellanos, J. V.; Revista de Sanidad y Asistencia Social 1945, 10, 109.

28. Rey, L.; Pessoa, S. B.; Revista Clínica de São Paulo 1953, 29, 85.

29. Sturrock, R. F.; Caribbean Journal of Science 1974, 14, 149.

30. Pointier, J. P.; Salvat, B.; Delplanque, A; Golvan, Y.; Ann. of Parasitology 1977, 52, 277.

31. Michelson, E. H.; Mota, E.; Revista do Instituto de Medicina Tropical 1982, 24, 75.

32. Patience, R. L.; Thomas, J. D.; Sterry, P. R.; Comp. Biochem. Physiol. 1983, $76,253$.

33. Freitas, J. R.; Alves, C. W.; De Marco, J. P.; Rocha, L. A.; Santos, M. B. L.; Ciência e Cultura 1990, 42, 667.

34. Gazin, P.; Barbosa, C. S.; Boury, M.; Audry, P.; Revista da Sociedade Brasileira de Medicina Tropical 2000, 33, 22.

35. Giovanelli, A.; Silva, C. L. P. A.; Leal, G. B. E.; Baptista, D. F.; Memórias do Instituto Oswaldo Cruz 2005, 100, 169.

36. Agência Estadual de Meio Ambiente e Recursos Hídricos de Pernambuco; Monitoramento das Bacias Hidrográficas do Estado de Pernambuco, Recife, 2003.

37. Thomas, J. D.; Powles, M. L.; Lodge, M. L.; The Biological Bulletin 1976, $151,386$.

38. Marxen, J. C.; Becker, W.; Comp. Biochem. Physiol. 2000, 127, 235.

39. Heneine, I. F.; Santos, M. C.; Gazzinelli, G.; Anais da Academia Brasileira de Ciências 1970, 42, 171.

40. Brayner, F. M. M.; Tese de Doutorado, Universidade Federal de São Carlos, Brasil, 1998.

41. Esteves, F. de A.; Fundamentos de Limnologia, $2^{\text {a }}$ ed., Interciência: São Paulo, 1988.

42. Lyra, L. T.; Muniz, T. M.; Revista Brasileira Malariologia e Doenças Tropicais 1983, 35, 56.

43. Freitas, J. R. de; Santos, M. B. L. dos Em Tópicos de Malacologia Médica; Barbosa, F. S., ed.; Fiocruz: Rio de Janeiro, 1995, cap. 6.

44. Vidotti, E. C.; Rollemberg, M. C. E.; Quim. Nova 2004, 27, 139. 